\title{
The Analysis of the Ultrasonic Welding Performance for the Medical Protective Clothing
}

\author{
Serkan BOZ1 (iD) 0000-0002-2989-1105 \\ Mehmet KÜÇÜK² (iD 0000-0002-0017-5762 \\ ${ }^{1}$ Ege University Faculty of Fashion and Design, Izmir, Turkey \\ ${ }^{2}$ Ege University Engineering Faculty Textile Engineering Department, Izmir, Turkey
}

Corresponding Author: Mehmet KÜÇÜK, mehmet.kucuk@ege.edu.tr

\begin{abstract}
Today, the global pandemic environment has made the medical protective clothing such as surgical mask a part of our lives. Thus, these products must be used not only by the healthcare personnel but also by everyone. However, among all of these protective products, those produced with the correct methods must be preferred. The aim of this study is to analyse the changes in the weight and production methods of the selected textile surfaces and the changes in the bursting strength, water resistance and air permeability of the seam area after ultrasonic welding process of these surfaces. As the results of this study, the air permeability of $50 \mathrm{gr} / \mathrm{m}^{2} \mathrm{SMS}$ fabric, the water resistance property of the joining of $45 \mathrm{gr} / \mathrm{m}^{2}$ SMMS and $50 \mathrm{gr} / \mathrm{m}^{2}$ SMS fabric types with the flat roller and the bursting strength of the joining of the fabric type produced with the $45 \mathrm{gr} / \mathrm{m}^{2} \mathrm{SMS}$ technic with the flat roller showed a better performance than any other alternatives.
\end{abstract}

\author{
ARTICLE HISTORY \\ Received: 16.10.2020 \\ Accepted: 16.03.2021
}

\section{KEYWORDS}

Medical protective clothing, ultrasonic welding, pandemic, face mask

\section{INTRODUCTION}

At the point where today's world has come, the protective textile products are extremely important in the protection of people from external threats. Especially in the protection from the health-threatening factors which impede our lives, such as the biggest international problem of today Covid19, the importance of the medical textile products is unquestionable.

Coating technology is used for the purpose of providing functionality to the textile surfaces (e.g. woven, knitted, nonwoven fabrics) with various methods. Regarding to coating technology, the permeability of the textile surfaces can be restricted, and these surfaces can be provided with air-liquid impermeability properties. The restriction of air and liquid permeability is desired also for the medical protective clothing.

The research and studies show that nonwoven fabrics are more protective than the uncoated woven and knitted fabrics in the control of the post-operative infections. Nonwoven fabrics which are treated with antimicrobial agents are used in medicine in order to provide maximum protection. For the materials treated in this way, surgical drape, device cases, mayo tables, surgical kits can be given as example [1].

If the pore size of the fabric which are used in the production of clothes used for the medical protection is smaller than the microorganism size, the penetration of the microorganisms can be prevented. However, it is not easy to produce a fabric with this size of pores. For this purpose, either coating techniques are used or the products with the same effect can be obtained by being sewn 2 or 3 layers on top of each other in order to reduce the penetration through these pores [2].

Since the coating technique provides the fabrics with extra properties, it has a wide area of use. This type of fabrics is highly used in the fields such as medical textiles, home

To cite this article: Boz S., Küçük M. 2021. The analysis of the ultrasonic welding performance for the medical protective clothing. Tekstil ve Konfeksiyon, 31(1), 53-62. 
textile, industrial textiles, geotextiles, automotive textiles, protective clothing and sports textiles in the textile sector as well as the agriculture and construction industries [3].

Especially the textile surfaces the permeability properties of which are required to be restricted need to maintain these properties when joined. Hence, because needle holes occur in the fabric during the joining of this type of surfaces, ultrasonic welding technique which is one of the thermal bonding methods is preferred instead of conventional sewing techniques.

Ultrasonic welding technique is frequently used in the fields of medicine, automotive, sports, textile and apparel. In this study, the nonwoven textiles which are used for medical clothing for which there is a great need today, the necessity for the joining of these surfaces with which type of joining method and the suitability of this method to its purpose were searched.

From the research made in this field, in a study by Kurşun Bahadır and Şahin in 2019, they welded stainless steel conductive yarns on top of the fabrics by using ultrasonic welding method in order to create an e-textile power transmission system [4]. In 2019, Şevkan Macit and Tiber investigated the difference of water permeability properties of joint points which occurred as the result of joining of fabrics coated with polyurethane membrane by using ultrasonic welding method when compared with conventional sewing methods [5]. In the study by Çeven and Karakan Günaydın in 2018, 18 different types of fabric were selected and analysed in order to identify the influence of weft density and yarn structure on the moisture management and air permeability properties [6]. In 2018, Şevkan Macit and Tiber used three types of woven fabric coated with polyurethane membrane to investigate the seam strength, bursting strength and bending properties of fabrics sewn with ultrasonic welding method. The fabrics were sewn ultrasonically and conventionally with various parameters. The fabrics sewn in both methods were washed and the properties of the fabrics were tested before and after the washing process. In the study that was made by Şevkan Macit and Tiber, different types of fabrics and different stitch types were compared. However, in this study, different production methods belonging to the same fabric type (nonwoven) and different weights were compared only with ultrasonic welding technique. [7]. In 2017 Eryürük et al. investigated the ultrasonic welding technique of nonwovens. This technique and the sewing techniques of surgical gowns with nonwovens were analysed. In this study, conventional sewing technique and ultrasonic welding technique were applied on the nonwoven surfaces and compared [8]. In the study of Y1lmaz Akyürek and Güneş dated 2016, joining examples on suitable fabrics in the work are used to determine the different views that formed by ultrasonic welding on the fabric. Based upon its different appearance and style compared to conventional seams, it was aimed to use this difference in women outwear. For this, the fashionable ladies' coats and jackets suitable for today's fashion were designed and one of them was stitched as a prototype product. So, a different practice of using ultrasonic welding in garment industry was presented to sector for the purpose of being an example [9]. In a study by Shi et al. in 2016, waterproof performance of seam produced by ultrasonic welding method was tested. Accordingly, it was determined that the problem of water penetration resulted from the needle holes [10]. In 2014, Kayar et al. analysed the effects of different roller types on the seam tensile properties in the ultrasonic welding method [11]. In a study by Kayar and Mistık, the mechanical properties of ultrasonically welded nonwoven fabrics were investigated. As mechanical property, tensile strength and the values of elongation at break properties were assessed [12].

The aim of the medical textile products (mask, overalls, surgical drapes, etc.) is to minimize the risk for the patients and healthcare personnel to infect each other mutually with air-borne (droplets) and water-borne (water, blood, saliva) viruses. As a personal protection equipment, these clothing pose an obstacle to the pathogens which are air-borne and water-borne. Regarding to these products, the sterile area remains sustainable.

It is thought that the air and water permeability of the fabric is affected negatively since needle holes occur in the seam points of the products which are sewn with conventional sewing technique (lock stitch, overlock, overedge stitches, etc.). In order to avoid losing these permeability values, ultrasonic welding technique which is based on the principle of thermal bonding of the synthetic materials was preferred for the joining of fabrics in this study.

The ultrasonic welding machine is as follows (Figure 1).

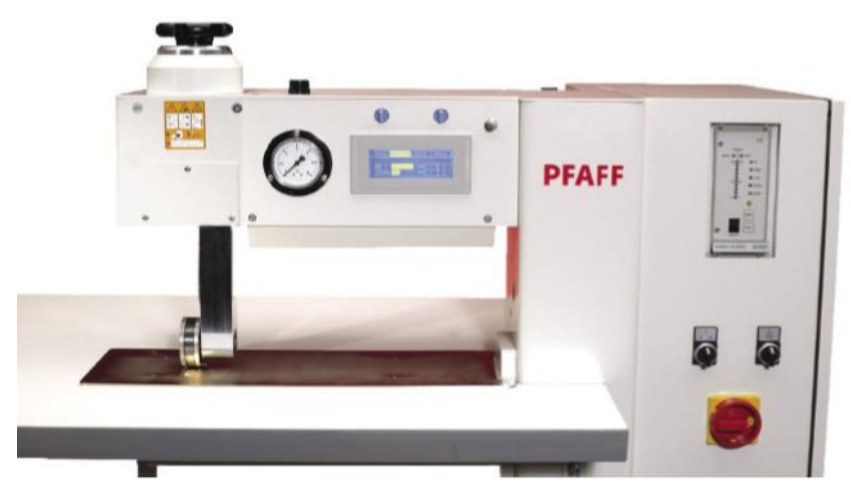

Figure 1. Pfaff 8310 Seamsonic ultrasonic welding machine

The advantages of ultrasonic welding machines are as follows:

\footnotetext{
- Joins the small pieces easily

- Provides a smooth and proper joining (patterned joining points are available upon request depending on the roller type)

- No smell or smoke during the sewing (joining) process

- No need for any needle, thread, shuttle-bobbin, etc. [13].
} 
Thus, the aim of this study is to analyse and numerically interpret the changes in the weight in grams and production methods of the selected textile surfaces, the air permeability and water resistance properties of these surfaces after joined with ultrasonic welding method, and the changes of the bursting strength in the seam area. All of the tests were applied to both the fabric surfaces and the sewing lines centred on the test devices and all comments were made comparing the results obtained. In this study, differently from the studies in the literature, 3 fabrics of equal weight that were obtained from different production methods (belonging to the same fabric type-nonwoven) and 3 fabrics of different weights that were obtained by the same production method were compared.

\section{MATERIAL AND METHOD}

\subsection{Material}

The nonwoven surfaces which are frequently used in the medical textile products and have less air permeability constitute the material of this study. The raw materials of these selected fabrics are kept constant as $100 \%$ PP. The properties of these fabrics are as follows (Table 1).

Table 1. The analysed fabric properties

\begin{tabular}{lcc}
\hline & $\begin{array}{c}\text { Weights } \\
\left(\mathbf{g r} / \mathbf{m}^{\mathbf{2}}\right)\end{array}$ & $\begin{array}{c}\text { Production } \\
\text { method }\end{array}$ \\
\hline Fabric-1 & 35 & SMS \\
Fabric-2 & 45 & SPUNBOND \\
Fabric -3 & 45 & SMS \\
Fabric -4 & 45 & SMMS \\
Fabric -5 & 50 & SMS \\
\hline
\end{tabular}

SMS and SMMS methods are preferred in the disposable products. These surfaces consist of separate layers joined thermally. The lower and upper layers specified as $\mathrm{S}$ comprise of Spunbond and the middle layers specified as $\mathrm{M}$ comprise of Meltblown material. The meltblown materials are formed by melting the polymer into a fibrous state. The middle layer of the material acts as a filter and prevents the undesirable penetrations. The outer surfaces are responsible for the mechanical properties of the material [13].

The spunbond materials are obtained from continuous fibres which are formed by the melting and shaping of the polyester layers through spinning method. Nonwoven surface production can be made from polymer directly and continually by the spunbond process. The surgical gowns produced by using $100 \%$ polypropylene spunbond are used in the market [13].

In order not to harm the smooth surface of the fabric obtained by the coating of the fabrics and not to reduce the strength and permeability properties by making needle holes, it is desired for this type of fabrics to be sewn by the techniques which provide thermal bonding with each other such as ultrasonic welding technique instead of conventional sewing techniques.
The piece that performs the sewing (welding) process by being in contact with the fabric in ultrasonic welding machines is called roller. Two types of rollers were used in the ultrasonic welding machine during the tests. These rollers were plain (flat) and diamond patterned. The width of both rollers are $8 \mathrm{~mm}$.

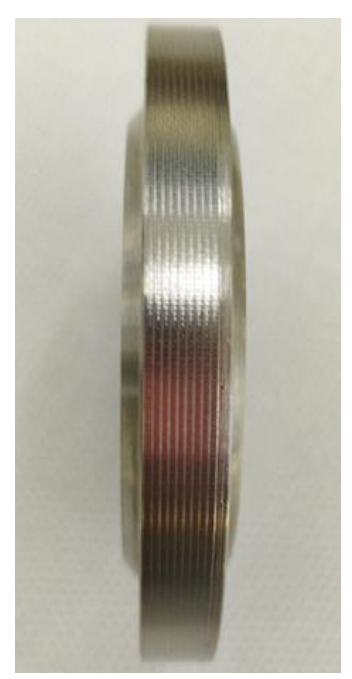

(a)

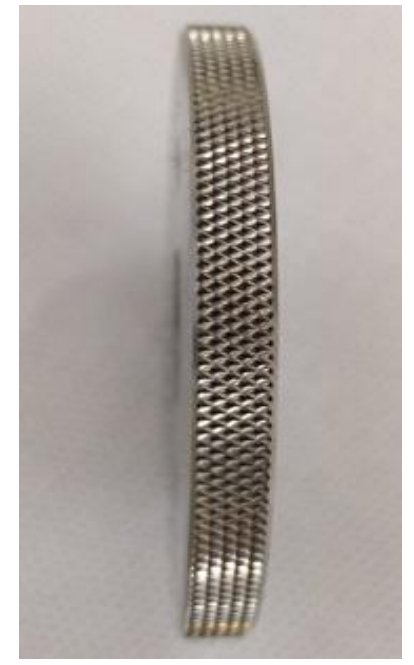

(b)
Figure 2. Ultrasonic rollers a. Flat patterned b. Diamond patterned

The seams made by using roller types shown in Figure 2 are as follows (Figure 3). The properties of the fabrics joined with these rollers were tested.

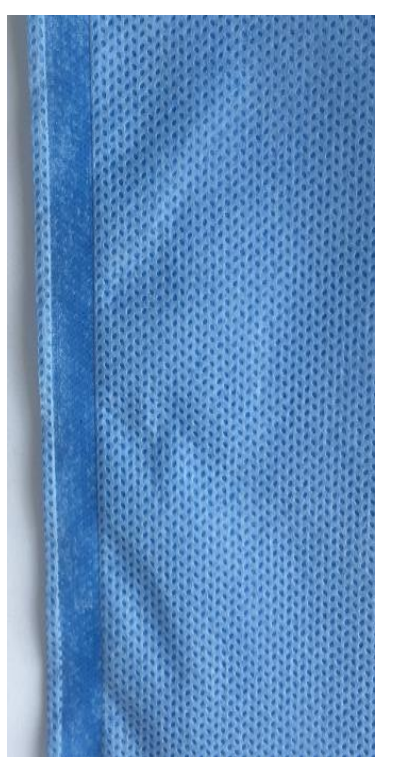

(a)

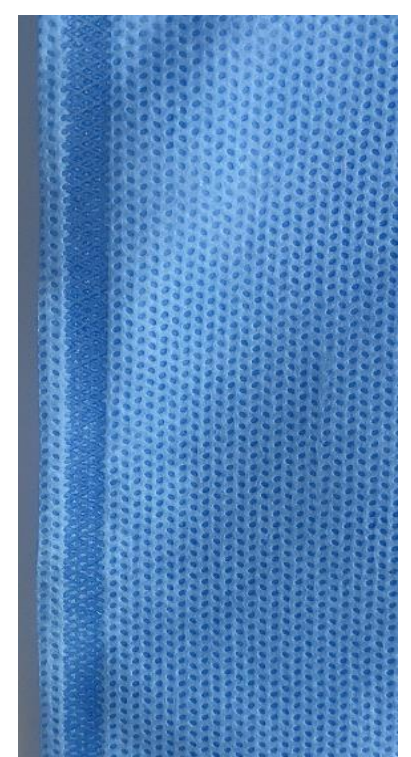

(b)
Figure 3. The images of ultrasonic seams a. Flat patterned b. Diamond patterned

In order to determine the appropriate machine parameters for the fabric types in the ultrasonic welding machines, it is necessary to perform test sewing on that fabric type by changing the parameters. In line with the pretesting, it was determined that the machine parameters in which the most productive sewing was obtained in the tested fabric types were $50 \%$ ultrasonic power, $45 \mathrm{dm} / \mathrm{min}$ and the distance between the rollers is $0.7 \mathrm{~mm}$ (Figure 4). 

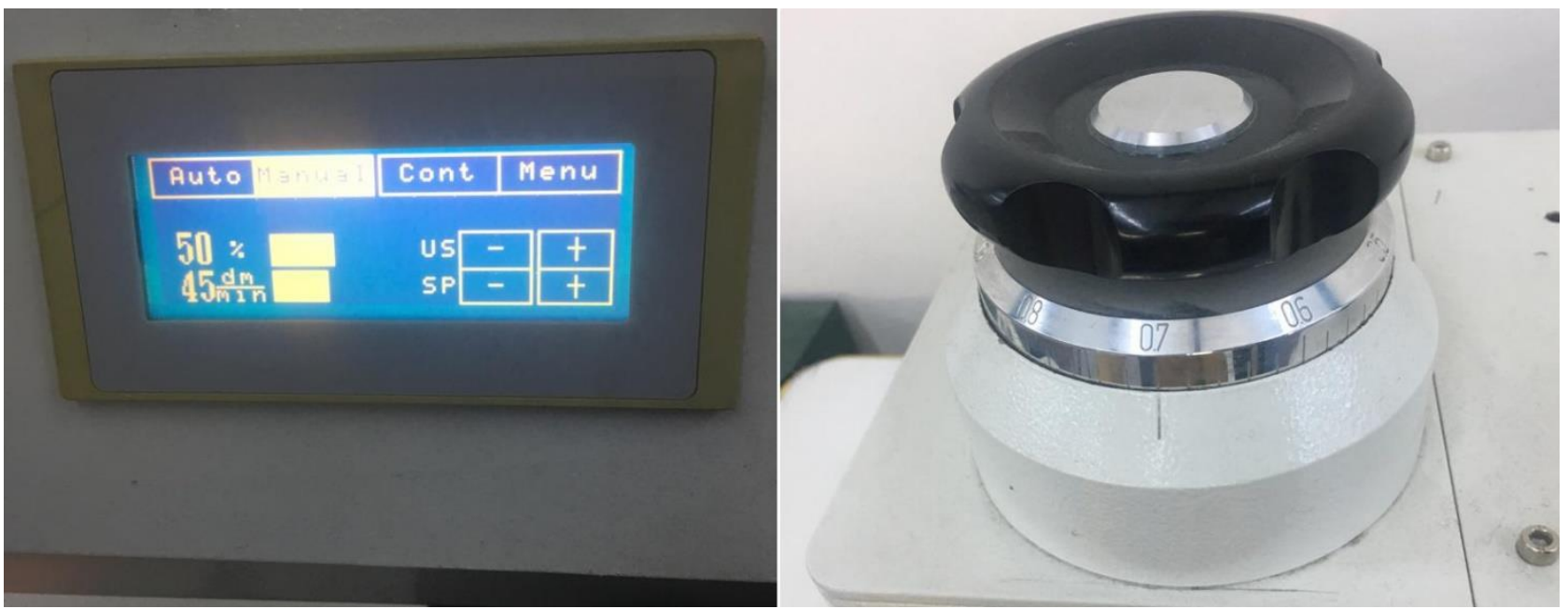

Figure 4. Machine parameters

\subsection{Method}

For the purpose of providing medical protection of the seam areas after the ultrasonic joining of the surfaces were completed, the air permeability and water resistance properties were analysed with the help of tests. Apart from these tests, it was intended to control the strength of the joint areas of the medical apparels while worn and used. The decrease in the strength of the joint areas means that these areas are damaged while worn and used and the property of protection is lost. In order to perform the control in question, the bursting strength tests were applied to the samples. The surfaces were conditioned in standard atmospheric conditions at $20{ }^{\circ} \mathrm{C} \pm 2$ and $65 \pm 4 \%$ relative humidity before testing.

\section{- Air Permeability Test}

One of the important signs of the comfort feeling in fabrics is the air permeability properties of the fabrics [14]. Besides, it can be controlled with the air permeability test whether the fabrics with functional properties (waterproofing, air impermeability, nonflammability, etc.) have the air impermeability property in question. The air permeability tests were performed with "Textest FX 3300 Air Permeability Tester" (Figure 5) in compliance with the ASTM D 1776 standard [16]. The tests were performed five times in each sample. Among the obtained results, the lower value was evaluated as better for allowing less air permeability.

\section{- Water Resistance Test}

The water resistance concept of fabric is described as the ability to resist the wetting by and the penetration of the water [15]. It is required for the medical products to have the water (blood, saliva, etc.) resistance property. The water resistance tests were performed in compliance with the TS EN ISO 811 standard [17]. The tests were performed five times in each sample. Among the obtained results, the lower value was evaluated as better for allowing less water permeability.

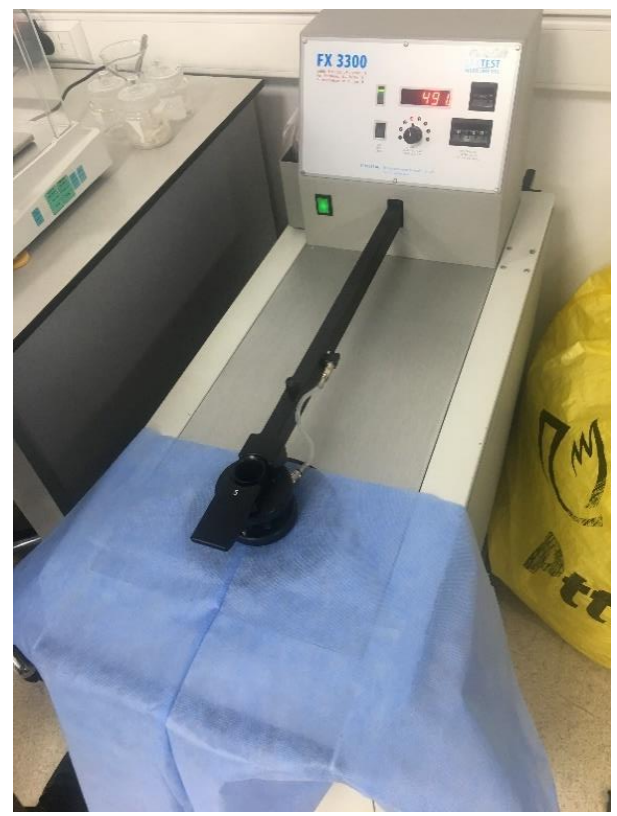

Figure 5. Textest FX 3300 Air Permeability Tester

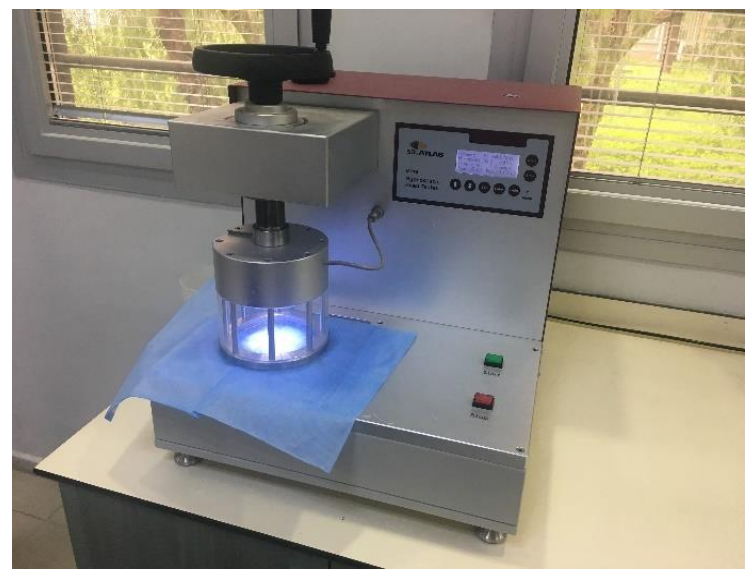

Figure 6. Water resistance tester 
The data obtained from the tests performed in the seamless surfaces and the joint areas joined by the ultrasonic method are presented in the findings section. The comparisons between the two areas show the property changes in the ultrasonic seam areas of the fabrics.

\section{- Bursting Strength Test}

The bursting strength test is mostly applied to the knitted and nonwoven fabrics. The bursting strength test of the coated surfaces is usually performed with the membrane technique. The bursting of the fabric during the multidirectional pressure application with any fluid underneath the fabric which is placed on the rubber membrane and the fluid pressure necessary for bursting the fabric are measured and determined [3]. The bursting strength test was performed in compliance with the ASTM D 751-06 standard [18]. The tests were performed five times in each sample. Among the obtained results, the higher value was evaluated as better for resisting more pressure.
The effects of different roller types, nonwoven production techniques and nonwoven weights variables on air permeability, water resistance and bursting strength were analyzed statistically with the One Way ANOVA analysis.

\section{RESULTS AND DISCUSSION}

In previous studies, the effect of nonwoven types on physical properties and comparison of the conventional sewing techniques with ultrasonic sewing were analyzed. In this study, the effects of different roller types, nonwoven production techniques and nonwoven weights variables on air permeability, water-resistance and bursting strength were investigated.

The tests performed within the scope of the standards defined after the fabrics were conditioned and the obtained data are shown in the tables (Table 2-4) below. For a better view of the results, the graphics below were created (Figure 7-9).

Table 2. Air permeability values of the fabric (seamless region) and the seam areas

\begin{tabular}{|c|c|c|c|c|c|c|c|c|}
\hline \multicolumn{9}{|c|}{ AIR PERMEABILITY $\left(5 \mathrm{~cm}^{2}, 100 \mathrm{~Pa}, \mathrm{~L} / \mathrm{m}^{2} / \mathrm{s}\right)$} \\
\hline \multirow{4}{*}{$35 \mathrm{gr} / \mathrm{m}^{2} \mathrm{SMS}$} & & 1 & 2 & 3 & 4 & 5 & Avg. & $\begin{array}{l}\text { Std. } \\
\text { Deviation }\end{array}$ \\
\hline & Fabric & 710 & 684 & 651 & 698 & 590 & 666.6 & 48.174 \\
\hline & Flat & 365 & 377 & 408 & 403 & 287 & 368 & 48.672 \\
\hline & Diamond & 502 & 566 & 456 & 480 & 475 & 459.8 & 42.522 \\
\hline \multirow{3}{*}{$\begin{array}{c}45 \mathrm{gr} / \mathrm{m}^{2} \\
\text { Spunbond }\end{array}$} & Fabric & 192 & 197 & 161 & 166 & 180 & 179.2 & 15.706 \\
\hline & Flat & 198 & 180 & 168 & 202 & 231 & 195.8 & 24.004 \\
\hline & Diamond & 200 & 210 & 176 & 210 & 197 & 198.6 & 13.921 \\
\hline \multirow{3}{*}{$45 \mathrm{gr} / \mathrm{m}^{2} \mathrm{SMS}$} & Fabric & 298 & 266 & 290 & 278 & 283 & 283 & 12.124 \\
\hline & Flat & 144 & 120 & 170 & 181 & 161 & 155.2 & 23.889 \\
\hline & Diamond & 273 & 309 & 285 & 330 & 326 & 304.6 & 25.025 \\
\hline \multirow{3}{*}{$45 \mathrm{gr} / \mathrm{m}^{2} \mathrm{SMMS}$} & Fabric & 193 & 190 & 183 & 180 & 173 & 183.8 & 7.981 \\
\hline & Flat & 161 & 168 & 177 & 156 & 159 & 164.2 & 8.408 \\
\hline & Diamond & 197 & 201 & 202 & 186 & 191 & 195.4 & 6.804 \\
\hline \multirow{3}{*}{$50 \mathrm{gr} / \mathrm{m}^{2} \mathrm{SMS}$} & Fabric & 134 & 127 & 123 & 133 & 117 & 126.8 & 7.085 \\
\hline & Flat & 136 & 119 & 108 & 114 & 131 & 121.6 & 11.674 \\
\hline & Diamond & 160 & 145 & 153 & 155 & 146 & 151.8 & 6.300 \\
\hline
\end{tabular}

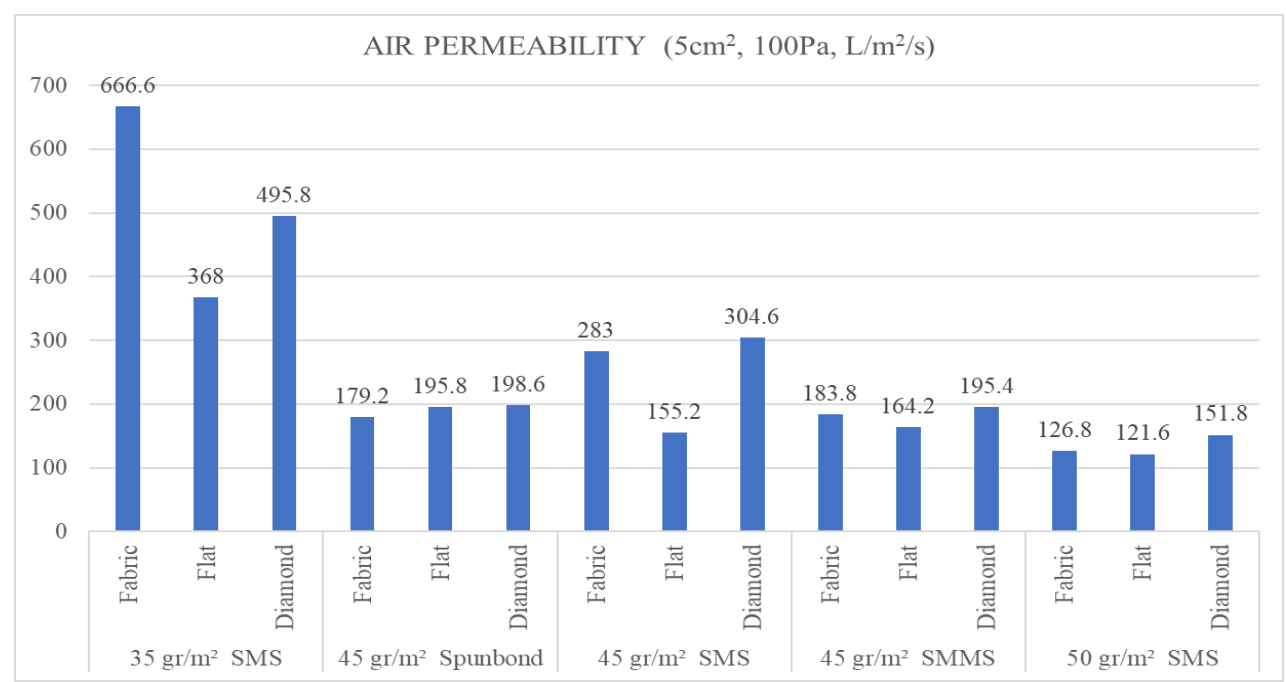

Figure 7. Air permeability values of the surfaces and seam areas 
Considering the data obtained from the air permeability tests:

- The air permeability decreases as the weight values increases in the surfaces produced with the same method.

- In general, the air permeability of the joint areas decreases noticeably thanks to providing a continuous joining when the flat roller is preferred. This shows that the property of protection is increased. However, the spaces due to the pattern of the diamond shaped roller, the air permeability cannot be prevented exactly as in the flat roller. As a result of this, values close to the fabric air permeability value are obtained from the areas made from the joining with the diamond patterned roller.

- The effect of roller types preferred in the ultrasonic welding process which is used in the joining of the surfaces with the same weight in grams but produced with different methods on the air permeability was also investigated. According to this, it was determined that the fabric with the highest air permeability was SMS (283 $\left.1 / \mathrm{m}^{2} / \mathrm{s}\right)$ followed by the SMMS $\left(183.8 \mathrm{l} 1 / \mathrm{m}^{2} / \mathrm{s}\right)$ and Spunbond $\left(179.2 \mathrm{l} / \mathrm{m}^{2} / \mathrm{s}\right)$ fabrics. While Spunbound $\left(195,8 \mathrm{l} / \mathrm{m}^{2} / \mathrm{s}\right)$ was the one that had the most air permeation in the joint areas of the surfaces which were joined by the flat roller, followed by the SMMS method with $164,21 / \mathrm{m}^{2} / \mathrm{s}$ and the SMS method with $155,21 / \mathrm{m}^{2} / \mathrm{s}$.

Table 3. Water resistance values of the fabric (seamless region) and seam areas (Water increase rate $600+-30 \mathrm{~mm} / \mathrm{min}$ )

\begin{tabular}{|c|c|c|c|c|c|c|c|c|}
\hline \multicolumn{9}{|c|}{ WATER RESISTANCE $\left(\mathrm{mmH}_{2} \mathrm{O}\right.$ column) } \\
\hline \multirow{4}{*}{$35 \mathrm{gr} / \mathrm{m}^{2} \mathrm{SMS}$} & & 1 & 2 & 3 & 4 & 5 & Avg. & $\begin{array}{c}\text { Std. } \\
\text { Deviation }\end{array}$ \\
\hline & Fabric & 140 & 150 & 155 & 130 & 135 & 142 & 10.368 \\
\hline & Flat & 260 & 275 & 270 & 265 & 260 & 266 & 6.519 \\
\hline & Diamond & 180 & 185 & 180 & 190 & 175 & 182 & 5.700 \\
\hline \multirow{3}{*}{$\begin{array}{l}45 \mathrm{gr} / \mathrm{m}^{2} \\
\text { Spunbond }\end{array}$} & Fabric & 320 & 310 & 315 & 325 & 330 & 320 & 7.905 \\
\hline & Flat & 390 & 395 & 385 & 380 & 390 & 388 & 5.700 \\
\hline & Diamond & 340 & 345 & 350 & 345 & 345 & 345 & 3.535 \\
\hline \multirow{3}{*}{$45 \mathrm{gr} / \mathrm{m}^{2} \mathrm{SMS}$} & Fabric & 310 & 315 & 305 & 305 & 310 & 309 & 4.183 \\
\hline & Flat & 350 & 350 & 345 & 360 & 350 & 351 & 5.477 \\
\hline & Diamond & 340 & 340 & 350 & 355 & 345 & 346 & 6.519 \\
\hline \multirow{3}{*}{$45 \mathrm{gr} / \mathrm{m}^{2} \mathrm{SMMS}$} & Fabric & 350 & 355 & 360 & 360 & 350 & 355 & 5 \\
\hline & Flat & 650 & 650 & 655 & 650 & 645 & 650 & 3.535 \\
\hline & Diamond & 430 & 435 & 435 & 440 & 430 & 434 & 4.183 \\
\hline \multirow{3}{*}{$50 \mathrm{gr} / \mathrm{m}^{2} \mathrm{SMS}$} & Fabric & 420 & 420 & 425 & 420 & 425 & 422 & 2.738 \\
\hline & Flat & 670 & 675 & 680 & 665 & 670 & 672 & 5.700 \\
\hline & Diamond & 470 & 475 & 480 & 465 & 460 & 470 & 7.905 \\
\hline
\end{tabular}

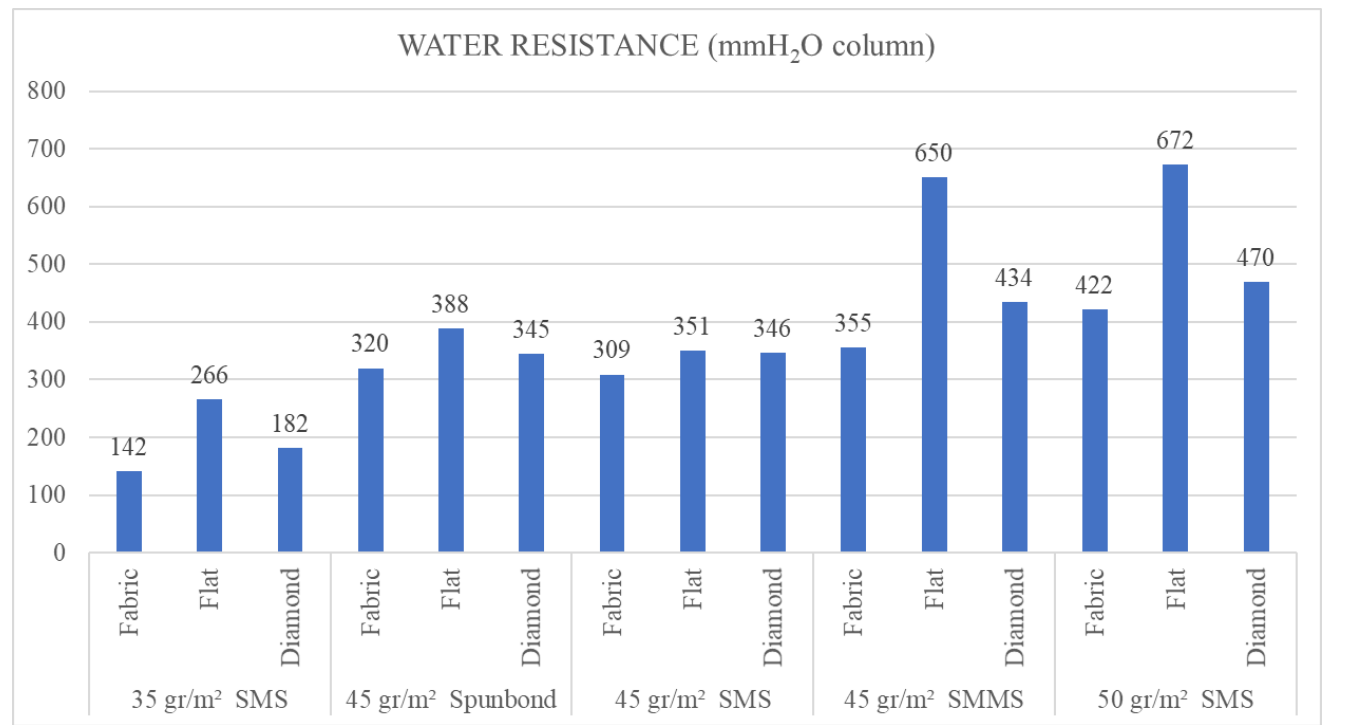

Figure 8. Water resistance values of the surfaces and seam areas 
Considering the data obtained from the water resistance tests:

- As the weight values of the surfaces produced with the same method increase, their water resistance properties improve. This improvement applies also to both the fabric surface and the joining types of the surfaces.

- Comparing the water resistance properties of the surfaces with the same weight in grams but produced with different methods, it can be said that the fabric preventing the water penetration the most is SMMS method, when the least preventing is the SMS method. This also applies to the joint areas in the joining of the surfaces with the flat and diamond roller types. However, when the joining methods are compared within themselves, the joints produced by the flat roller type showed higher water resistance property than those produced by the diamond roller types.

Table 4. Bursting strength test of the fabric (seamless region) and the seam areas

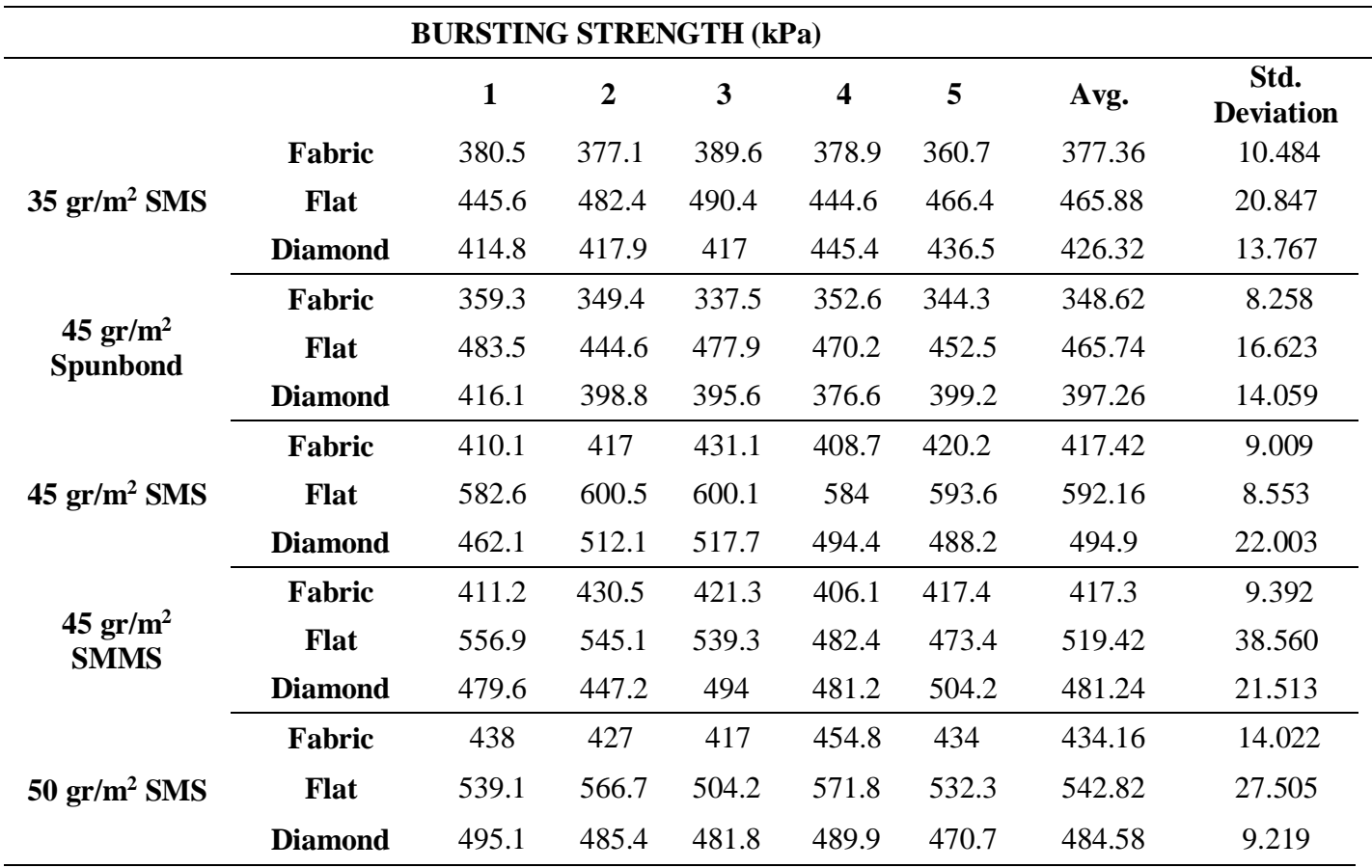

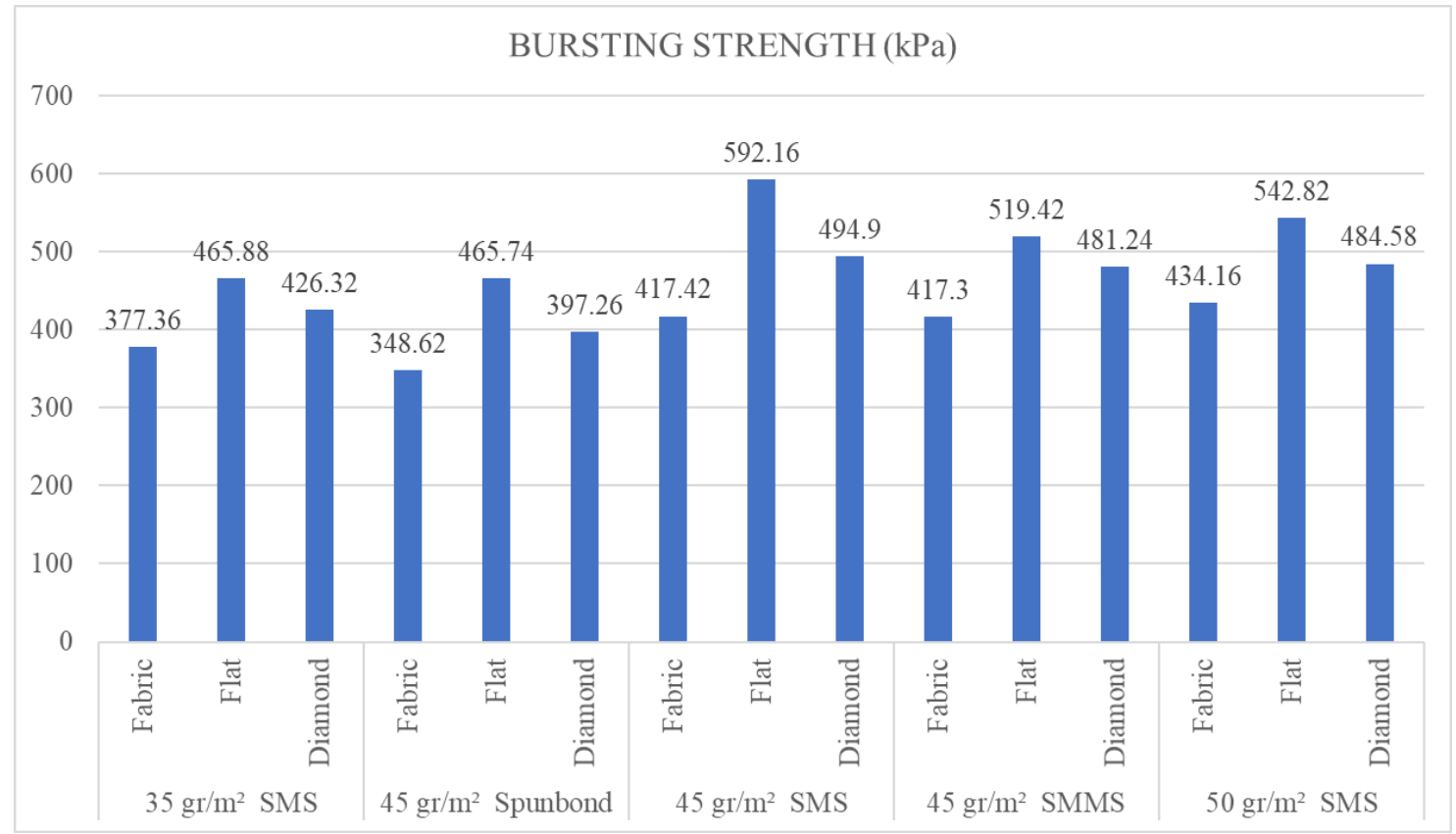

Figure 9. Bursting strengths of the surfaces and seam areas 
Considering the data obtained from the bursting strength tests:

- As the weight values of the surfaces produced with the same method increase, the bursting strengths increase. This improvement applies also to both the fabric surface and the joining types of the surfaces.

- Comparing the bursting strengths of the surfaces with the same weight in grams but produced with different methods, it was observed that the surface with the highest strength was the one produced with SMS method and the surface with the lowest strength was the one produced with Spunbond method. This also applies to the joint areas in the joining of the surfaces with the flat and diamond roller types. However, when the joining methods are compared within themselves, the joints produced by the flat roller type showed a higher bursting strength than those produced by the diamond roller types.

Considering the ANOVA analysis of the hypotheses that were examined throughout the study above, when looking at the significance value of the hypotheses (Table 5), there is a significance difference in the hypotheses $\mathrm{H} 2-\mathrm{H} 9$ $(\mathrm{p}<0,05)$, but there is no in the H1 ( $>>0,05)$.

\section{CONCLUSIONS}

The textile surfaces to be used for medical protection and the joining methods used in the transformations of these surfaces into a product are highly important. When the surface choice determines the level of protection from the risks, the joining techniques are required not to cause a significant change, deterioration and deficiency in the determined protection levels.

Within the scope of this study, the surface that needed to be preferred in order to provide medical protection, and the air permeability and water resistance properties of the seam areas were analysed after the completion of the ultrasonic joining processes of these surfaces. The strength values of the joint areas of the medical apparels while worn and used were analysed as well. The decrease in the strength of the joint areas means that these areas are damaged while worn and used and the property of protection is lost.

In conclusion, considering the fabric production methods and the joint types:

- It was observed that the air permeability property of the $50 \mathrm{gr} / \mathrm{m}^{2}$ SMS fabric showed a better performance than the other alternatives and there was not a major change in its air permeability property during the joining.

- It was observed that the joining of the $45 \mathrm{gr} / \mathrm{m}^{2} \mathrm{SMMS}$ and $50 \mathrm{gr} / \mathrm{m}^{2}$ SMS fabric types with flat roller showed a better performance than any other alternatives, considering its water resistance property.

- It was determined that the joining of the fabric type produced with the $45 \mathrm{gr} / \mathrm{m}^{2}$ SMS technique had a better result than any other alternatives, considering its performance against the bursting strength.

When looking at the air permeability and water resistance test results, inversely proportional graphs are seen as expected (Figure 7-8).

Table 5. ANOVA test analysis

\begin{tabular}{lll}
\hline & \multicolumn{1}{c}{ Hypothesis } & Sig. \\
\hline H1 & $\begin{array}{l}\text { There is a NOT statistically significant difference (at 95\% confidence interval) between different roller } \\
\text { types (fabric, flat or diamond) in aspect of air permeability values. }\end{array}$ & 0,098 \\
H2 & $\begin{array}{l}\text { There is a statistically significant difference (at 95\% confidence interval) between different production } \\
\text { technique (SMS, Spunbond and SMMS) in aspect of air permeability values. }\end{array}$ & 0,006 \\
H3 & $\begin{array}{l}\text { There is a statistically significant difference (at 95\% confidence interval) between different weights (35, 45 } \\
\text { and 50) in aspect of air permeability values. }\end{array}$ & 0,000 \\
H4 & $\begin{array}{l}\text { There is a statistically significant difference (at 95\% confidence interval) between different roller types } \\
\text { (fabric, flat or diamond) in aspect of water resistance. }\end{array}$ & 0,000 \\
H5 & $\begin{array}{l}\text { There is a statistically significant difference (at 95\% confidence interval) between different production } \\
\text { techniques (SMS, Spunbond and SMMS) in aspect of water resistance. }\end{array}$ & 0,005 \\
H6 & $\begin{array}{l}\text { There is a statistically significant difference (at 95\% confidence interval) between different weights (35, 45 } \\
\text { and 50) in aspect of water resistance. }\end{array}$ & 0,000 \\
H7 & $\begin{array}{l}\text { There is a statistically significant difference (at 95\% confidence interval) between different roller types } \\
\text { (fabric, flat or diamond) in aspect of bursting strength. }\end{array}$ & 0,000 \\
H8 & $\begin{array}{l}\text { There is a statistically significant difference (at 95\% confidence interval) between different production } \\
\text { techniques (SMS, Spunbond and SMMS) in aspect of bursting strength. }\end{array}$ & 0,001 \\
H9 & $\begin{array}{l}\text { There is a statistically significant difference (at 95\% confidence interval) between different weights (35, 45 } \\
\text { and 50) in aspect of bursting strength. }\end{array}$ & 0,023 \\
\hline
\end{tabular}


It is considered that this study will be a guide for the businesses producing functional products in the medical area. Additionally, it is thought that it will be useful to analyse the points that should be taken into consideration during other apparel processes (such as spreading, cutting, ironing) in the future studies.

Our previous experiments and heuristic trials of determining the parameters at the beginning of this research show that, it is necessary to increase the ultrasonic power or to decrease the sewing speed in order to decrease air and water resistance values. However, there might be more heat on the fabric surfaces in these circumstances and this might cause the loss of strength in the sewing (joining) line. Besides, increasing the distance between the rollers will provide the optimum joining as the fabric thickness increases.

In the welding processes, the relation between the gap, speed, and the ultrasonic power is if the gap and the sewing speed are kept too low, the fabrics may be damaged. Oppositely, if these values are kept too high, merging will not occur. More melting levels can be obtained when the ultrasonic power is increased more than necessary. This may damage the fabric. Antithetically, if this power is lower than needed then the merging will not occur. Keeping the ultrasonic welding parameters constant can cause different physical properties, especially in similar fabrics with different weights.

Today, the increasing pandemics all around the world have made the protective clothing such as surgical masks a part of our lives. Thus, these protective products must be used not only by the healthcare personnel but also by everyone.

Among many alternatives of the protective products like mask, those produced with the correct methods must be preferred. It is getting easier to make the right choices thanks to the determination of these methods which is one the aims of this study. For example, it is expected that rather than the use of the masks produced with the conventional sewing techniques (front middle seam) (Figure 10-a) [19], the use of masks which are produced with the ultrasonic joining methods (Figure 10-b-c-d) [20] will help this situation be more sustainable by providing the desired protection.

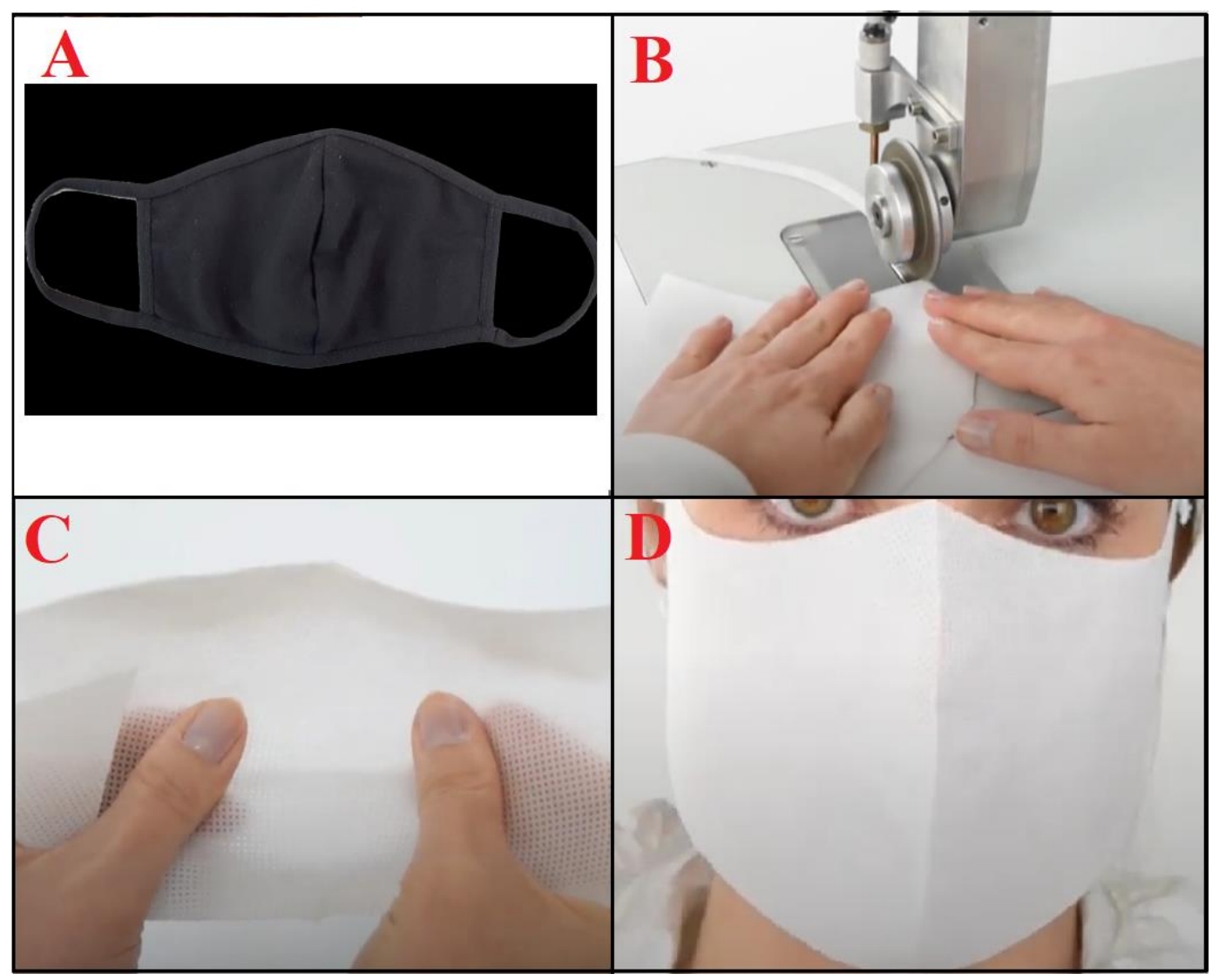

Figure 10. Protective mask examples 


\section{REFERENCES}

1. Hayes SF, Curtis White W. 2011, February 24. How Antimicrobial Treatment Can Improve nonwoven fabrics. Retrieved from http://www.aegisasia.com/How_Antimicrobial_Treatment_Can_Impr ove.pdf.

2. Behera BK, Arora H. 2009. Surgical Gown: A Critical Review. Journal of Industrial Textiles, 38, 205.

3. Bulut Y. 2010. Mechanical properties of coated fabrics suitable for garments, Dokuz Eylül Üniversitesi Fen Bilimleri Enstitüsü Yüksek Lisans Tezi, İzmir.

4. Kurşun Bahadır S, Şahin UK. 2019. Measured current characteristics of powered e-textile transmission lines with respect to welding process parameters. Tekstil ve Konfeksiyon, 29(2), 97-104.

5. Şevkan Macit A., Tiber B. 2019. Investigation of Water Permeability of Ultrasonic Seaming on PU Coated Fabrics. Int. Per. of Recent Tech. in App. Eng. 1: 44-49.

6. Çeven EK, Karakan Günaydın G. 2018. Investigation of Moisture Management and Air Permeability Properties of Fabrics with Linen and Linen-Polyester Blend Yarns. Fibres \& Textiles in Eastern Europe, 26, 4(130): 39-47.

7. Şevkan Macit A, Tiber B. 2018. An Investigation on Ultrasonic Seaming in Woven Fabrics. Dokuz Eylül Üniversitesi-Mühendislik Fakültesi Fen ve Mühendislik Dergisi, 20 (59), 566-575.

8. Eryürük SH, Karagüzel Kayaoğlu B, Kalaoğlu F. 2017. A study on ultrasonic welding of nonwovens used for surgical gowns. International Journal of Clothing Science and Technology, 29(4), 539-552.

9. [9] Yılmaz Akyürek B, Güneş M. 2016. The applied investigation and the usage in woman's outwear designs of ultrasonic sewing. Inönü University Journal of Art and Design, 6(13), 251-261.

10. Hui Shi, Jianping Wang, Xiaona Chen, Shunhua Luo, Lingxi Zhang. 2016. Research on the seam performance of waterproof clothing based on continuous ultrasonic welding technology, International Journal of Clothing Science and Technology, 28(2):171 - 190.

11. Kayar M, Mistık Sİ, İnan D. 2015. Analysing effect of the factors on ultrasonic seam tensile properties of nonwoven fabrics by Nested
Anova Design. International Journal of Clothing Science and Technology, 27(6), 803-817.

12. Kayar M, Mistık Sİ. 2014. Effect of Fiber Type and Polyethylene Film on Mechanical Properties of Ultrasonically Bonded Multi Layer Nonwoven Fabrics. Tekstil ve Konfeksiyon, 24(1), 30-36.

13. Boz S. 2008. Investigation of ultrasonic energy usage in apparel industry. Ege Üniversitesi Fen Bilimleri Enstitüsü Yüksek Lisans Tezi. İzmir.

14. Küçük M. 2018. Redesigning the functionality properties of football goalkeeper jerseys. Ege Üniversitesi Fen Bilimleri Enstitüsü Doktora Tezi. İzmir

15. Turan RB. 2012. Relationships between permeability properties and structural-geometrical properties of fabrics. Dokuz Eylül Üniversitesi Fen Bilimleri Enstitüsü Doktora Tezi. İzmir.

16. ASTM D1776 / D1776M-20, Standard Practice for Conditioning and Testing Textiles, ASTM International, West Conshohocken, PA, 2020, www.astm.org

17. TS EN ISO 811 - Textiles - Determination of resistance to water penetration - Hydrostatic pressure test (ISO 811:2018) Available at: https://intweb.tse.org.tr/Standard/Standard/Standard.aspx?081118051 11510805110411911010405504710510212008811104311310407309 8054053054098082067109085104077

18. [18] ASTM D751-19, Standard Test Methods for Coated Fabrics, ASTM International, West Conshohocken, PA, 2019, www.astm.org.

19. Malin Z. 2020, Face masks: The most purchased masks we've recently covered, Available at: https://www.nbcnews.com/shopping/ apparel/ popular-face-masks-cdc-valves-n1236806

20. "Simple method for the production of protective masks", Available at: https://www.pfaff-industrial.com/en/news/mar-25-2020-simplemethod-for-the-production-of-protective-masks 